\title{
Avaliação das boas práticas agropecuárias de propriedades leiteiras da Serra
}

\section{Gaúcha-RS}

\author{
Evaluation of the good agricultural practices of dairy farms in Serra Gaúcha-RS \\ Evaluación de las buenas prácticas agrícolas y ganaderas en las explotaciones lecheras de Serra \\ Gaúcha-RS
}

Jeferson Aloísio Ströher

ORCID: https://orcid.org/0000-0002-5314-9269 Universidade Estadual do Rio Grande do Sul, Brasil E-mail: jeferson.stroher@hotmail.com

Magnólia Martins Erhardt

ORCID: https://orcid.org/0000-0003-3730-2515 Universidade Estadual do Rio Grande do Sul, Brasil E-mail: magnolia-erhardt@uergs.edu.br

Voltaire Sant'Anna

ORCID: https://orcid.org/0000-0003-3348-0592 Universidade Estadual do Rio Grande do Sul, Brasil E-mail:voltaire-santanna@uergs.edu.br

Neila Silvia Pereira dos Santos Richards

ORCID: https://orcid.org/0000-0001-6610-5567

Universidade Federal de Santa Maria, Brasil E-mail: neilarichardsprof@gmail.com

Hans Fröder

ORCID: https://orcid.org/0000-0003-1551-236X Universidade Estadual do Rio Grande do Sul, Brasil

E-mail: hans-froder@uergs.edu.br

Luís Carlos Oliveira dos Santos Junior

ORCID: https://orcid.org/0000-0001-5532-502X Universidade Estadual do Rio Grande do Sul, Brasil E-mail: luisc.oliveirajr@gmail.com

Marion Ruis

ORCID: https://orcid.org/0000-0001-8920-2378 Universidade Estadual do Rio Grande do Sul, Brasil E-mail:marionruis@univates.br

Ismael Petter

ORCID: https://orcid.org/0000-0003-4931-4433 Unidade Central de Educação Fai Faculdades, Brasil E-mail: ismaelpetter@hotmail.com

\begin{abstract}
Resumo
As Boas Práticas Agropecuárias (BPA) na produção de leite constituem um conjunto de atividades desenvolvidas dentro da propriedade rural com objetivo de garantir a saúde, o bem-estar e a segurança dos animais, do homem e do ambiente. Deste modo, o trabalho teve como objetivo avaliar o cumprimento das BPA implementadas na execução do plano de qualificação de fornecedores de leite estabelecidos pela Instrução Normativa (IN) $\mathrm{n}^{\circ}$ 77/2018 do Ministério da Agricultura, Pecuária e Abastecimento (MAPA) em 12 propriedades da Serra Gaúcha-RS das quais foram analisados os dezesseis itens desta legislação. Os itens de maiores inconformidades são os controle integrado de pragas (96\%), higiene pessoal e capacitação dos trabalhadores (92\%), uso racional e estocagem de produtos químicos, agentes tóxicos e medicamentos veterinários (82\%), e falta de informação distribuição de material técnico como manuais e cartilhas (67\%) indicando um baixo nível de adequação às BPA no setor leiteiro no que preconiza a legislação avaliada nas propriedades visitadas, assim demonstrando a necessidade de incrementar ações de qualidade para que haja melhorias em relação à integridade físico-química e microbiológica do leite cru refrigerado produzido por estes produtores rurais. Palavras-chave: Boas práticas agropecuárias; Leite cru refrigerado; Qualidade do leite; Instrução Normativa $n^{\circ} 77 / 18$.
\end{abstract}

\footnotetext{
Abstract

The Good Agricultural Practices (GAP) in milk production constitute a set of activities developed within the rural property in order to ensure the health, welfare and safety of animals, humans and the environment. Thus, the work aimed to evaluate compliance with the GAP implemented in the execution of the qualification plan for milk suppliers established by the Normative Instruction (IN) No. 77/2018 of the Ministry of Agriculture, Livestock and Supply
} 
(MAPA) in 12 properties in Serra Gaúcha-RS of which the sixteen items of this legislation were analyzed. The items of major nonconformities are the integrated pest control (96\%), personal hygiene and training of workers $(92 \%)$, rational use and storage of chemicals, toxic agents and veterinary drugs (82\%), and lack of information distribution of technical material such as manuals and booklets $(67 \%)$ indicating a low level of adequacy to GAP in the dairy sector in what the legislation advocates in the visited properties, thus demonstrating the need to increase quality actions so that there are improvements in relation to the physical-chemical and microbiological integrity of raw refrigerated milk produced by these rural producers.

Keywords: Good agricultural practices; Raw refrigerated milk; Milk quality; Normative Instruction No. 77/18.

\section{Resumen}

Las Buenas Prácticas Agrícolas (BPA) en la producción de leche constituyen un conjunto de actividades desarrolladas dentro de la propiedad rural con el fin de garantizar la salud, el bienestar y la seguridad de los animales, el hombre y el medio ambiente. De esta forma, el trabajo tuvo como objetivo evaluar el cumplimiento de las BPA implementadas en la ejecución del plan de calificación de proveedores de leche establecido por la Instrucción Normativa (IN) $n^{\circ} 77 / 2018$ del Ministerio de Agricultura, Ganadería y Abastecimiento (MAPA) en 12 propiedades de Serra Gaúcha-RS de las cuales se analizaron los dieciséis ítems de esta legislación. Los ítems de mayor no conformidad son el control integrado de plagas (96\%), la higiene personal y la capacitación de los trabajadores (92\%), el uso y almacenamiento racional de productos químicos, agentes tóxicos y medicamentos veterinarios (82\%), y la falta de distribución de información de material técnico como manuales y folletos $(67 \%)$ indicando un bajo nivel de adecuación a las BPA en el sector lechero en lo que la legislación preconiza en las propiedades visitadas, demostrando así la necesidad de aumentar las acciones de calidad para que haya mejoras en relación a la integridad físico-química y microbiológica de la leche cruda refrigerada producida por estos productores rurales.

Palabras clave: Buenas prácticas agrícolas; Leche cruda refrigerada; Calidad de la leche; Instrucción Normativa ${ }^{\circ}$ $77 / 18$.

\section{Introdução}

As boas práticas agropecuárias (BPA) estão associadas ao processamento de derivados lácteos seguros e de qualidade, com respaldo à sustentabilidade ambiental e à possibilidade de agregação de valor aos produtos, além de ser uma exigência dos consumidores e da legislação (Embrapa, 2005). A implantação correta destas boas práticas na propriedade rural assegura que o leite e seus derivados estejam adequados e dentro dos parâmetros da legislação brasileira (Brasil, 2018). Segundo Fernandes (2011), a eficácia das ações das BPA depende do planejamento econômico da propriedade, sendo que melhorias quanto às pastagens, produção de silagem, aquisição de concentrados e investimentos em tecnologias de manejo e conservação do produto deverão ser realizadas. Sendo assim, as áreas que devem ser observadas na implantação das BPA são a saúde animal, higiene na ordenha, nutrição, bem-estar animal, meio ambiente e gestão socioeconômica (Fao e Idf, 2013).

De acordo com a Instrução Normativa (IN) no 77 do Ministério da Agricultura, Pecuária e Abastecimento (MAPA) (Brasil, 2018), o estabelecimento receptor de leite deve implementar o autocontrole e o plano de qualificação de fornecedores de leite, devendo contemplar a assistência técnica e gerencial, bem como a capacitação de todos os seus fornecedores, com foco em gestão da propriedade e implementação das boas práticas agropecuárias.

A aplicação das BPA é uma alternativa para minimizar os riscos de contaminação nas diferentes etapas do processo de produção, pois esses procedimentos são capazes de reduzir a contaminação microbiana e alterações físico-químicas no leite, podendo reduzir em média $87 \%$ da contagem padrão em placas (CPP) (Vallin et al., 2009) com consequente melhoria da qualidade do leite e rápido retorno do capital investido (Paixão, 2014).

Considerando a dificuldade observada pelos produtores para se adequarem aos novos parâmetros legais, se mostra importante o monitoramento e estudo das condições dos leites atualmente produzidos no Rio Grande do Sul (RS). Assim, o presente estudo tem o objetivo de avaliar a adequação de 12 propriedades leiteiras da Serra Gaúcha-RS às novas legislações do MAPA. 


\section{Metodologia}

Foram visitadas 12 propriedades produtoras de leite cru refrigerado em 3 municípios da Serra Gaúcha-RS (Garibaldi, Coronel Pilar e Boa Vista do Sul), sendo no total 4 propriedades em cada município no ano de 2019. A estratégia de investigação utilizada foi descritiva, aplicada e exploratória de abordagem qualitativa quantitativa e utilizou como instrumento a recolha de dados utilizando um questionário impresso checklist, estruturado com 50 questões objetivas e subjetivas baseadas no Plano de Qualificação dos Fornecedores de Leite (PQFL) disposto na IN nº 77/2018 (Brasil, 2018), também foi realizado a avaliação das BPA foi realizada através de inspeção visual em todas as propriedades.

Os dados recolhidos a partir da análise quantitativa das perguntas foram tabulados de forma organizada e analisados por distribuição de frequência de acordo com a categoria de variáveis. Além disso, a análise qualitativa foi realizada com uma avaliação comparativa constante das perguntas subjetivas e respostas dos entrevistados.

A IN 77 (Brasil, 2018) explana que na execução do plano de qualificação de fornecedores de leite devem contemplar no mínimo 16 (dezesseis) itens, conforme podemos verificar na Tabela 1.

Tabela 1. Itens do plano de qualificação de fornecedores de leite segundo Brasil (2018).

\begin{tabular}{cl}
\hline Item & \multicolumn{1}{c}{ Boas práticas agropecuárias a serem avaliadas } \\
\hline I & Manejo sanitário \\
\hline II & Manejo alimentar e armazenamento de alimentos \\
\hline III & Qualidade da água \\
\hline IV & Refrigeração e estocagem do leite \\
\hline V & Higiene pessoal e saúde dos trabalhadores \\
\hline VI & Higiene de superfícies, equipamentos e instalações \\
\hline VII & Controle integrado de pragas \\
\hline VIII & Capacitação dos trabalhadores \\
\hline IX & Manejo de ordenha e pós-ordenha \\
\hline X & Adequação das instalações, equipamentos e utensílios para produção de leite \\
\hline XI & Manejo de resíduos e tratamento de dejetos e efluentes \\
\hline XII & Uso racional e estocagem de produtos químicos, agentes tóxicos e medicamentos veterinários \\
\hline XIII & Manutenção preventiva e calibragem de equipamentos \\
\hline XIV & Controle de fornecedores de insumos agrícolas e pecuários \\
\hline XV & Fornecimento de material técnico como manuais, cartilhas, entre outros \\
\hline XVI & Adoção de práticas de manejo racional e de bem-estar animal \\
\hline
\end{tabular}

Fonte: adaptado (Brasil, 2018).

De acordo com a Empresa de Assistência Técnica e Extensão Rural (Emater/RS, 2020), no ano de 2020 o estado do Rio Grande do Sul possuía 65.202 propriedades leiteiras vinculadas às indústrias de laticínios. Desta forma, o critério de escolha das propriedades consistiu na localização em um raio de 20 quilômetros do laticínio parceiro deste estudo, que está situado na região da Serra Gaúcha-RS.

As propriedades foram devidamente codificadas de $\mathrm{A}$ à $\mathrm{M}$, a fim de manter a integridade dos produtores. Para avaliação das BPA, foram acompanhadas as rotinas das propriedades sendo seguida uma ordenha do começo ao fim e analisadas todas as rotinas praticadas durante o período de meio turno de trabalho na propriedade.

\section{Resultados e Discussão}

A Figura 1 mostra os itens que apresentaram conformidade e não conformidades frente as observações registradas nos itens descritos na IN 77, de I a XVI (Brasil, 2018). 
Figura 1. Verificação do percentual (\%) de propriedades que estão adequadas ou não aos itens (I à XVI) preconizados nas BPA conforme a IN no 77 (Brasil, 2018).

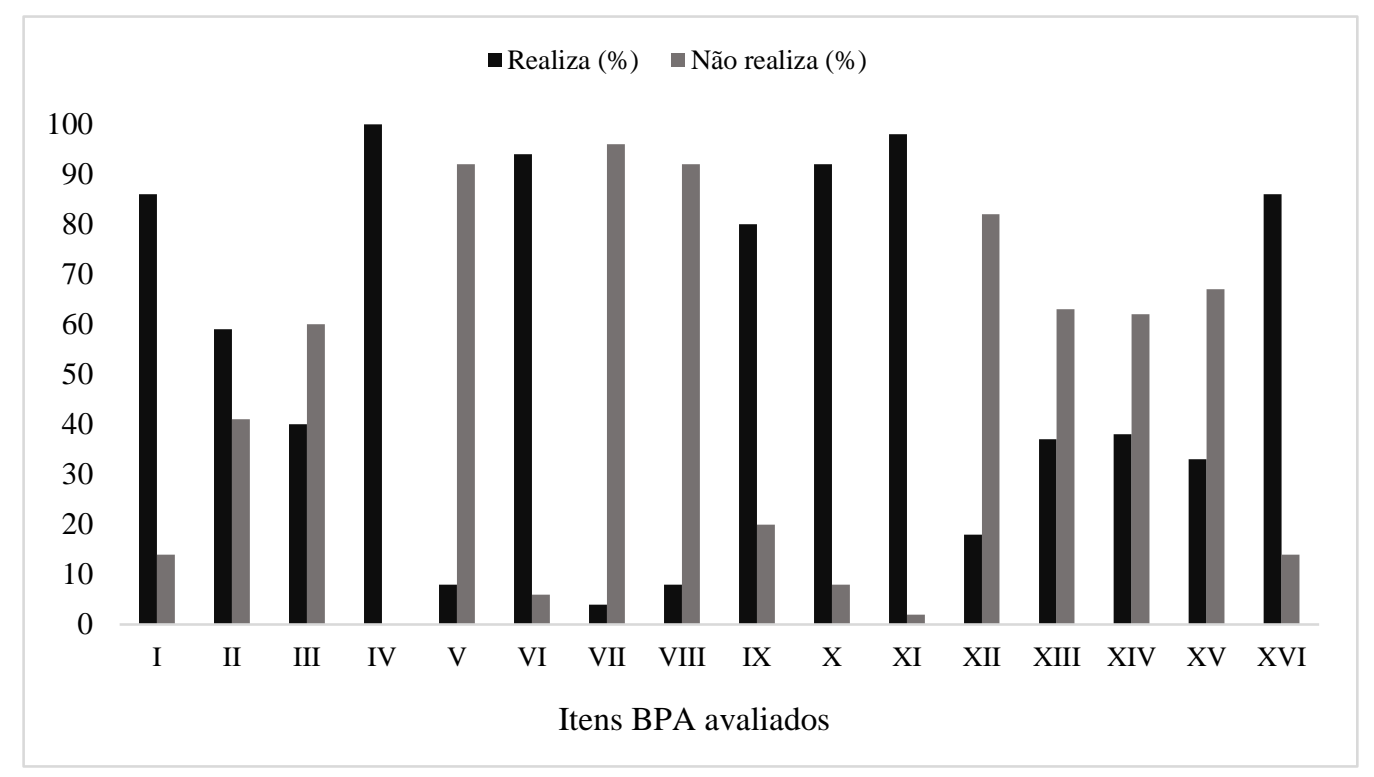

Fonte: Autores (2021).

Os maiores percentuais de conformidade, em ordem decrescente, são os itens IV (refrigeração e estocagem do leite) e XI (manejo de resíduos e tratamento de dejetos e efluentes) (Figura 1).

O cuidado com a refrigeração e estocagem do leite (IV) é prioridade para todos os produtores com $100 \%$ de conformidade, sendo que os tempos e as temperaturas de resfriamento do leite devem obedecer a limites estabelecidos e o tanque de armazenamento deve ter capacidade proporcional ao volume de leite produzido. O tanque de refrigeração deve ser capaz de manter o leite na temperatura requerida até a coleta e o acesso a ele deve ser mantido livre, sem obstruções ou dificuldade de passagem (Brasil, 2019). O resfriamento do leite na propriedade é de grande importância para a excelência em sua qualidade, pois é responsável por diminuir a deterioração do leite pelas bactérias psicrotróficas (Santos et al., 2009).

O manejo dos resíduos e tratamento de dejetos e efluentes (XI) específicos devem ser descritos para a especificação do descarte de leite, animais mortos, destinação de plásticos, produtos fitossanitários entre outros e as áreas de armazenamento de dejetos devem ser instaladas de forma adequada, considerando seu impacto visual, presença de odores, risco de poluição e de proliferação de pragas. Observou-se que $83 \%$ das propriedades têm preocupação com este aspecto, com manejo adequado do esterco dos animais e descarte de leite inadequado para o consumo, porém nas propriedades inconformes houve a constatação de contaminação de mananciais com o despejo dos dejetos sem seu devido tratamento.

Segundo Sindileite (2020), os resíduos oriundos da propriedade rural são os materiais que não são aproveitados, podendo ser sólido ou líquido. Quanto à destinação, os resíduos devem ser tratados e destinados em local apropriado. O esterco do estábulo e da sala de ordenha devem ser removidos diariamente, e dispostos em local específico, distante das salas de leite e ordenha, para evitar a proliferação de moscas.

A verificação da higiene de superfícies, dos equipamentos e instalações (VI) é um item que possui conformidade em 11 propriedades, uma vez que a maioria das propriedades possuem instalações, equipamentos e utensílios adequados para a produção de leite $(\mathrm{X})$. Uma má higiene dos equipamentos de ordenha, das instalações e do ordenhador, proporciona um aumento da contagem de micro-organismos no leite e a ocorrência de mastite (elevada contagem de células somáticas no leite). Portanto, é de suma importância a adequação de todas as propriedades quanto à higiene de todos os processos na propriedade, sendo que 
uma série de práticas higiênicas devem ser realizadas para evitar tais contaminações, como a higienização prévia dos tetos, das mãos do ordenhador e do local de ordenha (Spanamberg et al., 2009).

Ströher et al. (2020), verificaram inconformidade em 8 (50\%) das propriedades estudadas na primeira visita quanto ao item higiene de superfícies, equipamentos e instalações, onde foram encontradas sujidades nas teteiras da ordenha, na sala de resfriamento do leite e nas instalações em geral, sendo considerado pelos autores uma grande fonte de contaminação do leite.

Quanto aos aspectos da criação, manejo dos animais, ordenha, diagnóstico de doenças, vacinação e medidas de controle, todos os produtores se adequaram nestes aspectos.

O manejo sanitário (I) deve contemplar um programa de saúde do rebanho, tendo por objetivo manter todos os animais saudáveis e produtivos. Deve-se incluir práticas para o diagnóstico, prevenção, tratamento e controle de doenças relevantes (Brasil, 2019). Cabe salientar que em apenas uma propriedade (8,3\%) ainda não são realizados os exames de brucelose e tuberculose anualmente. No entanto, para tratamento das mastites clínicas, em 11 propriedades (92\%) há a identificação de animais em tratamento de medicamentos bem como controle de animais doentes e respectivos protocolos. Um ambiente higiênico, seco e confortável aos animais, visa diminuir as altas contagens de CCS no leite, sendo que os animais com os úberes sujos exigem maiores cuidados por ocasião da ordenha (Müller, 2002).

Segundo Müller (2002), os produtores devem realizar os exames de brucelose e tuberculose anualmente, assim como também preconiza a legislação brasileira (Brasil, 2018). A legislação em vigor (Brasil, 2018) diz que cada propriedade deve possuir um médico veterinário responsável e deve incluir os seguintes controles: controle sistemático de parasitoses; controle sistemático de mastites; e o controle de brucelose (Brucella abortus) e tuberculose (Mycobacterium bovis). No experimento não foi constatado um médico veterinário responsável pela propriedade, mas um profissional contratado pelo laticínio. Os animais que foram adquiridos pelas propriedades eram oriundos de propriedades cadastradas nos órgãos de defesa agropecuários e acompanhados de Guia de Trânsito Animal (GTA), atestados de sanidade animal, principalmente brucelose e tuberculose, livres de mastite e foram mantidos em pasto separado (quarentena) (Sindileite, 2020).

Dentre os pontos positivos observados neste estudo está também a adoção de práticas de manejo racional e de bem-estar animal (XVI), sendo que a maioria das propriedades adotam as técnicas de manejo e as instalações da propriedade garantem o bem-estar, porém em 11 propriedades (92\%) propriedades não há registros de treinamentos realizados para o manejo racional. Os produtores treinados e capacitados possuem grande avanço nos resultados da qualidade do leite quanto ao ganho das atividades gerais das propriedades, portanto, quando há uma padronização das ações na propriedade rural são verificadas melhorias num maior número de produtores simultaneamente. O produtor deve adotar práticas que mantenham os animais cercados de cuidados essenciais ao seu bem-estar, garantindo a máxima eficiência produtiva e reprodutiva, tendo em vista a importância dos controles zootécnicos e sanitários (Sindileite, 2020).

O controle zootécnico deve possuir a identificação e registro individual dos animais, o controle de produção individual (pesagem mensal do leite), da composição do leite, da parição das fêmeas, do ganho de peso das bezerras e novilhas, reprodutivo, de intervalo entre partos e da mortalidade dos animais. Quanto ao controle sanitário do rebanho, para produzir um leite seguro e de qualidade é necessário ter o controle rigoroso da saúde dos animais, obedecendo às legislações pertinentes (Sindileite, 2020).

Em relação ao manejo da ordenha e pós ordenha (IX), destaca-se o fato de que a inconformidade principal é o fato de não ser realizado o teste da caneca de fundo preto em todos os animais, assim como o estudo de Ströher et al., (2020), na primeira visita às propriedades, que também verificaram esta inconformidade em todos os produtores, este teste serve para o diagnóstico da mastite clínica dos animais em lactação.

Em 11 propriedades (92\%) não foi constatada a realização do teste de CMT (California Mastitis Test) nas vacas, recomendado para os animais em lactação pelo menos uma vez ao mês. Segundo Sindileite (2020), é necessário a retirada dos três primeiros jatos de leite de cada teto do animal em uma caneca de fundo preto e deve-se observar o seu aspecto que caso 
esteja alterado (com a presença de grumos, pus ou sangue), significa que aquele teto do animal está com a presença de mastite clínica e devendo ocorrer o descarte do leite. Nero et al. (2009), analisando diferentes perfis de produção leiteira em 60 propriedades em Minas Gerais, constatou que a maioria dos produtores (41-68,3\%) não realiza o CMT como teste de triagem, verificando a presença de mastites apenas pelo descarte dos primeiros jatos em caneca de fundo escuro ( $43,2 \%$ dos que descartam) ou no chão ( $9,1 \%$ dos que descartam).

A mastite clínica também contribui para a elevação da CCS do leite e é de fácil identificação, ao contrário da mastite subclínica que não apresenta sinal clínico visível no animal (Sindileite, 2020).

Os produtores devem ser qualificados quanto às práticas que garantam uma rotina de ordenha em condições higiênicas, sem lesionar e evitar a transmissão de doenças entre os animais. Não devem ser introduzidos contaminantes no leite e este, deve ser manipulado adequadamente após a ordenha. Os procedimentos de limpeza e sanitização dos equipamentos e higienização do úbere dos animais devem estar descritos e os trabalhadores qualificados para a realização dessas tarefas. Os equipamentos agrícolas e de infraestrutura não devem colocar em risco a saúde e a segurança dos colaboradores, sendo que as instalações devem ser adequadas ao porte dos animais a serem manejados (Brasil, 2019).

O manejo alimentar e armazenamento de alimentos (II) deve prever a aquisição de insumos de forma a manter um suprimento de nutrientes constante aos animais. A fim de se manter a qualidade dos alimentos, os mesmos devem ser armazenados em locais adequados e separados de insumos que possam resultar em contaminação acidental (Brasil, 2019). Neste quesito, a principal inconformidade encontrada foi que nenhum produtor realiza um manejo alimentar com ajustes na dieta do rebanho, embora todos os animais tenham identificação individual (100\%) e segundo Sindileite (2020), os alimentos fornecidos aos animais devem atender às exigências nutricionais dos animais e ser isentos de produtos que causem danos à saúde do rebanho e/ou ser humano e os produtos a serem utilizados na alimentação dos animais devem ser estocados protegidos da umidade, de pragas e de eventuais contaminantes químicos ou agroquímicos.

Com relação à água (III), 5 propriedades $(41,6 \%)$ têm problemas com a qualidade da água, sendo que 5 (41,6\%) propriedades não tem qualquer tratamento no fornecimento aos animais, bem como as mesmas não são analisadas em 8 propriedades $(66,6 \%)$. Conforme legislação, a água deve ser de boa qualidade tanto para fornecimento aos animais quanto para a higienização dos equipamentos, e devem ser estabelecidos procedimentos que visem a adequada proteção e captação das fontes naturais e higienização dos reservatórios (Brasil, 2019). A água não tratada das propriedades pode contaminar o leite por microorganismos de origem fecal. Também há uma preocupação com a utilização de água sem nenhum tratamento para a limpeza dos equipamentos de ordenha, sendo que pode haver o aumento imediato da contagem bacteriana total do leite. Segundo Ramines et al. (2009) e Silva (2011), o uso de água sem cloração para o enxágue final dos equipamentos de ordenha, pode contribuir para o aumento da CPP do leite cru refrigerado.

No controle de fornecedores de insumos agrícolas e pecuários (XIV), existe comando no estoque de insumos em 9 propriedades $(75 \%)$, porém em $100 \%$ das propriedades não há calendário de aquisição de insumos agrícolas. A escolha de fornecedores é importante para o fornecimento de insumos agrícolas e pecuários de qualidade, pois deve-se observar e somente adquirir insumos de fornecedores idôneos e que a qualidade dos produtos seja garantida. Contrário a este estudo, Ströher et al. (2020) em experimento com quinze produtores rurais verificaram na primeira visita, que 4 propriedades estavam em conformidade.

Em relação à manutenção preventiva e calibragem de equipamentos (XIII), 9 propriedades (75\%) apresentaram um cronograma de manutenção programada dos equipamentos, entretanto apenas em 6 (50\%) existe registro das manutenções executadas. A manutenção preventiva visa aumentar a vida útil dos equipamentos e a calibração dos equipamentos é essencial para o fornecimento de um produto de boa qualidade, pois falhas dos termostatos dos equipamentos de refrigeração podem resultar em preservação inadequada do leite (Brasil, 2019). Ströher et al. (2020), verificaram que em 6 propriedades existia um 
cronograma de manutenção programada e o registro das manutenções executadas nos equipamentos, porém nas demais 14 propriedades era inexistente estes procedimentos. Verifica-se a necessidade de fornecimento de material técnico como manuais, cartilhas, entre outros (XV), pois a falta de acesso à informação induz os produtores ao erro e consequentemente à perda de produtividade e a qualidade do leite (STRÖHER et al., 2020).

Quanto à verificação do uso racional e estocagem de produtos químicos, agentes tóxicos e medicamentos veterinários (XII), todas as propriedades estavam inconformes, assim como nos subitens: registro de treinamentos dos trabalhadores quanto ao uso de agroquímicos e produtos de uso veterinário; registro da aplicação dos agroquímico e o uso de equipamentos de proteção individual quando há aplicação dos mesmos. Deve haver também a separação em área específica dos agroquímicos e dos produtos de uso veterinário, devendo tais áreas ser de acesso restrito aos trabalhadores habilitados. Constatou-se que 11 propriedades (92\%) os colaboradores/trabalhadores das propriedades visitadas não possuem qualquer tipo de treinamento para a atividade.

Ströher et al. (2020), na primeira visita às propriedades, verificaram que em 13 propriedades (86,7\%) houve inconformidade também quanto ao item XIII, sendo que as inadequações apontadas foram a falta de registro de treinamentos dos trabalhadores quanto ao uso de agroquímicos e produtos de uso veterinário, registro da aplicação dos agroquímico e o uso de equipamentos de proteção individual quando há aplicação destes agroquímicos. Segundo a legislação brasileira (Brasil, 2019), a utilização de agroquímicos e produtos de uso veterinário deve ser realizada de acordo com a recomendação técnica e todos os trabalhadores deverão passar por programas de treinamento que evidenciem a importância do uso racional dos insumos e a sua correta forma de utilização.

Nenhum treinamento periódico foi ministrado junto aos produtores analisados (VIII). Devem ser considerados treinamentos dos trabalhadores quanto ao uso de equipamentos de proteção individual (EPI), técnicas de ordenha, manejo de bezerros, práticas de ordenha, uso racional de insumos, manejo racional dos animais, entre outros, sendo que todos os treinamentos realizados devem ser registrados e estar disponíveis. Discordando deste estudo, Ströher et al. (2020) verificaram de quinze propriedades apenas três possuíam treinamentos periódicos junto aos produtores. Sindileite (2020), relata que alguns treinamentos são de grande importância para os produtores de leite como para relações pessoais e interpessoais, boas práticas agropecuárias na produção de leite, manejo adequado do rebanho e ordenha, entre outros. Fao; Idf (2013) e Martinelli et al. (2014) destacam que produtores rurais deverão possuir treinamentos de todas as etapas da cadeia leiteira em que fazem parte, desde a ordenha em si, até o resfriamento do leite, armazenamento e transporte. No estudo de Battaglini et al., (2013) sendo analisadas 201 propriedades em cinco municípios da região central do Paraná, demonstrou que antes do início dos treinamentos, a média total da CPP era de 7,2 milhões UFC/mL e após o final dos treinamentos ministrados, houve uma diminuição significativa de quase $60 \%$ na média geral da CPP.

Outro aspecto importante e com alto índice de inconformidade é a saúde pessoal e saúde dos trabalhadores (V), pois os produtores de leite precisam considerar sua própria saúde e bem-estar. É preciso garantir que os equipamentos agrícolas e de infraestrutura não coloquem em risco a saúde e a segurança dos colaboradores e que EPI's, banheiros e pias devem estar disponíveis quando necessário. Exames médicos regulares e vacinação para colaboradores e animais para a prevenção de zoonoses devem ser considerados (Brasil, 2019). Ströher et al. (2020), verificaram inconformidade em todas as propriedades. Os autores relataram que não havia comprovação de exames de saúde dos trabalhadores rurais para a produção do leite.

Todas as propriedades analisadas estão não conformes quanto à disponibilidade de equipamentos de proteção individual (V) e em 10 propriedades (83,3\%) não existe local adequado para a higiene pessoal com fornecimento de água e sabão. Segundo a Cartilha de Orientações para o convívio seguro da Unicamp (2021) contra a covid-19, recomenda-se a higiene frequente das mãos (com água corrente e a utilização de sabão ou álcool em gel 70\%) no dia a dia antes de comer, depois de usar o banheiro, depois de assoar o nariz, tossir ou espirrar, e depois de tocar em superfícies como maçanetas, corrimãos, manuseio de lixo e utensílios compartilhados com outras pessoas, entre outros. 
A manipulação dos produtos como antiparasitários e de limpeza devem ser acondicionados em locais separados de outros produtos químicos de uso rotineiros e sua manipulação necessita do uso obrigatório de EPI. Segundo Brasil (2019), a área de armazenamento do leite deve possuir um local apropriado para a lavagem e secagem das mãos e ser de fácil limpeza.

Em uma pesquisa realizada por Ströher et al. (2021) com 51 produtores de leite da Serra Gaúcha e do Vale do TaquariRS, quanto às alterações nas rotinas nas propriedades leiteiras no enfrentamento da pandemia de covid-19, os autores relevaram que os produtores explanaram que os transportadores de leite utilizavam algum equipamento de proteção individual (EPI) para evitar a propagação da covid-19. Também em relação ao tipo de EPI utilizado, os produtores mencionaram ainda que 28 (55\%) usavam máscaras e 20 (39\%) transportadores de leite faziam uso de luvas.

Quanto à qualidade da água das propriedades (III), destaca-se que importante pelo processo de higienização dos equipamentos e das instalações, pois o uso da água de má qualidade nessas atividades se torna um importante meio de contaminação, inclusive do leite.

No que se refere às medidas de controle de pragas (VII), em 11 propriedades (92\%) é inexistente, entretanto não foi constatado a sua presença nos locais observados, discordando de Ströher et al (2020), que verificaram em duas propriedades rurais a inexistência de medidas de controle de pragas na primeira visita, sendo encontrada a presença de roedores na sala de resfriamento de leite em uma propriedade.

Medidas devem ser adotadas nas propriedades de forma a garantir o controle adequado de pragas em locais onde elas possam se reproduzir, introduzir doenças e/ou afetar a qualidade e segurança do leite. Ações de controle de pragas são necessárias na área de ordenha, locais de estocagem de alimentos e nos abrigos dos animais (Brasil, 2019). Segundo a Idf; Fao (2013), algumas espécies de pragas variam geograficamente e podem incluir animais nativos da região, roedores, pássaros e insetos. Portanto é necessário garantir que sejam eliminadas antes de se reproduzam, introduzam doenças e afetam a qualidade e a segurança do leite e dos produtores rurais que estão diretamente ligados ao processo de produção.

Ströher et al. (2020) avaliaram 15 propriedades leiteiras quanto às BPA segundo à IN 77 (Brasil, 2018), concluíram que após a adoção das BPA nas propriedades houve grande melhora nos resultados de CPP do leite cru refrigerado.

\section{Conclusão}

Os resultados apontam um baixo nível de adoção das BPA no setor leiteiro no que preconiza a IN nº77/18 do MAPA. Com a adoção de um Programa de BPA espera-se aumentar a qualidade e a rentabilidade do leite pelos pequenos produtores brasileiros. Faz-se também necessário uma maior abrangência deste estudo, atingindo maior número de propriedades leiteiras, verificando-se assim os gargalos da produção do leite cru refrigerado apontando as melhorias no processo de produção. Destacase a importância na elaboração de material informativo, capacitações, realização de visitas e treinamentos in loco, mostrando aos produtores a importância destes cuidados para a qualidade do produto e sanidade do rebanho e funcionários da propriedade rural.

\section{Nota}

Este artigo foi apresentado como resumo expandido/pôster no $7^{\circ}$ Simpósio de Segurança Alimentar - sbCTA-RS.

\section{Referências}

Battaglini, A. P. P., Fagnani, R., Dunga, K. S., \& Beloti, V. (2013). Difusão de boas práticas e caracterização de propriedades leiteiras. Arch. Zootec., Córdoba, 62(237), 151-154. http://scielo.isciii.es/scielo.php?script=sci_arttext\&pid=S0004-05922013001100117

Brasil. (2018). Ministério da Agricultura Pecuária e Abastecimento. Instrução Normativa nº 77. MAPA. Diário Oficial da República Federativa do Brasil

Brasil. (2019) Ministério da Agricultura Pecuária e Abastecimento. Guia orientativo para a elaboração do plano de qualificação de fornecedores de leite PQFL. Brasília, DF: MAPA. http://www.agricultura.gov.br/assuntos/producao-animal/arquivos-publicacoes-bem-estar-animal/guia-orientativo-paraelaboracao-do-pqfl 
Emater (2020). Área técnica. Bovinocultura de leite. http://www.emater.tche.br/site/area-tecnica/sistema-de-producao-animal/bovinos-deleite.php\#.Xp7p8WZKjIU

Embrapa (2005). Boas práticas agrícolas para produção de alimentos seguros no campo-elaboração de manual de boas práticas agropecuárias na produção leiteira. Brasília, PAS/EMBRAPA. 26p. (Manual técnico)

Food and Agriculture Organization of the United Nations (Fao); international Dairy Federation (Idf).(2013) Guia de boas práticas na pecuária de leite. Roma. (Produção e Saúde Animal Diretrizes, 8). http://www.fao.org/3/ba0027pt/ba0027pt.pdf

Lima, C. G.; Possa, C.; Helou, C.; Costa, E. B.; Helou, M.; Carnevalli, R.; \& Neo, S. A. N. (2008). Boas Práticas Agropecuárias - BPA. Sindileite-GO

Martinelli, R. R., Bánkuti, F. I., Bánkuti, S. M. S., de Brito, M. M., \& de Castro, P. L. (2014). A influência da assistência técnica e extensão rural na qualidade do leite in natura. Revista Varia Scientia Agrárias, 4(1), 09-22. http://e revista.unioeste.br/index.php/variascientiaagraria/article/view/9820/9045

Nero L. A., Viçosa, G. N., \& Pereira, F. E. V. Qualidade microbiológica do leite determinada por características de produção. Ciência e Tecnologia de Alimentos; 2009;29(2)386-390

Paixão, M. G. (2014) Impacto econômico da implantação das boas práticas agropecuárias relacionadas com a qualidade do leite. Revista Ceres, 61(5), 612621, http://www.redalyc.org/pdf/3052/305232579003.pdf

Ramires, C. H., Berger, E. L., \& Almeida, R. (2009). Influência da qualidade microbiológica da água sobre a qualidade do leite. Archives of Veterinary Science, 14(1), 36-42, http://revistas.ufpr.br/veterinary/article/view/12913

Santos, P. A., Silva, M. A. P.; Souza, C. M., Isepon, J. S., Oliveira, A. N.; \& Nicolau, E. S. (2009). Efeito do tempo e da temperatura de refrigeração no desenvolvimento de microrganismos psicrotróficos em leite cru refrigerado coletado na macrorregião de Goiânia, GO. Ciência Animal Brasileira, 10(4), 12371245

Silva, P. D. L., Paiva, A. D., Rangel, A. H. N., Carvalho, M. D. F., \& Lima Júnior, D. M. (2011). Influência das boas práticas de ordenha e da ordem de parto sobre a composição e CCS (CCS) do leite bovino. Revista Verde de Agroecologia e Desenvolvimento Sustentável, 6(3), 1-6, http://www.gvaa.com.br/revista/index.php/RVADS/article/view/655

Sindileite. Sindicato das Indústrias de Laticínios do Estado de Goiás. BPT. (2020). Boas Práticas de Transporte. http://gadoholandes.com/jornal/wpcontent/uploads/2016/07/MANUAL-BOAS-PRATICAS-AGROPECUARIAS.pdf

Spanamberg, A., Sanches, E. M. C., Santurio, J. M., \& Ferreiro, L. (2009). Mastite micótica em ruminantes causada por leveduras. Ciência Rural, 39, 282-290

Ströher, J. Á., Erhardt, M. M., Fröder, H., Ruis, M., \& Richards, N. S. P. dos S. (2021). Avaliação de alterações nas rotinas dos produtores de leite no enfrentamento da pandemia de COVID-19 no Vale do Taquari e na região da Serra Gaúcha, Estado do Rio Grande do Sul, Brasil. Research, Society and Development, 10(4), e48910414263, 10.33448/rsd-v10i4.14263. https://rsdjournal.org/index.php/rsd/article/view/14263

Ströher, J. A., dos Santos Jr, L. C., Erhardt, M. M., Fröder, H., \& Caxambu, S. (2020). Avaliação dos parâmetros microbiológicos e das boas práticas agropecuárias em propriedades leiteiras do Vale do Taquari-RS. VI Congresso Internacional das Ciências Agrárias. COINTER PDVAgro https://doi.org/10.31692/2526-7701.VCOINTERPDVAgro.0192. https://cointer.institutoidv.org/smart/2020/pdvagro/uploads/3514.pdf

Ufpel (Universidade Federal de Pelotas) (2016). Orientações para o convívio seguro. https://wp.ufpel.edu.br/ccz/files/2016/03/Controle-de-roedoressinantr\%C3\%B3picos-Saneamento.pdf

Vallin, V. M., Beloti, V., Battaglini, A. P. P., Tamanini, R., Fagnani, R., Angela, H. L., \& Silva, L. C. C. (2009). Melhoria da qualidade do leite a partir da implantação de boas práticas de higiene na ordenha em 19 municípios da região central do Paraná. Semina: Ciências Agrárias, 30(1), 181-188. http://www.uel.br/revistas/uel/index.php/semagrarias/article/viewFile/2661/2313

Fernades, L. L. V. (2011). Produção e qualidade do leite: um estudo de caso na Apelu. Porto Alegre. https://lume.ufrgs.br/bitstream/handle/10183/77550/000895181.pdf?sequence=1\&isAllowed=y

Ramires, C. H., Berger, E. L., \& Almeida, R. (2009). Influência da qualidade microbiológica da água sobre a qualidade do leite. Archives of Veterinary Science, 14(1), 36-42, 2009.

Unicamp. (2021). Orientações sanitárias para o enfrentamento da pandemia. (2021). https://www.unicamp.br/unicamp/cartilha-covid-19/orientacoes-sanitariaspara-o-enfrentamento-da-pandemia 